\title{
Successful strategies to increase the consumption of fruits and vegetables: results from the Danish ' 6 a day' Work-site Canteen Model Study
}

\author{
Anne Lassen*, Anne Vibeke Thorsen, Ellen Trolle, Mette Elsig and Lars Ovesen \\ Danish Veterinary and Food Administration, Institute of Food Safety and Nutrition, Mørkhøj Bygade 19, \\ DK-2860 Søborg, Denmark
}

Submitted 22 July 2002: Accepted 12 August 2003

\begin{abstract}
Objective: To investigate changes in the consumption of fruits and vegetables in worksite canteens using the tools of continuous quality improvement, and to gain knowledge of practical strategies being effective in increasing the consumption.

Design: Study design included baseline data collection, an $8 \mathrm{~h}$ training session for all canteen staff, goal setting, strategy development and implementation for each canteen, end-point data collection and a follow-up data collection 4 months from the end-point ( 1 year from baseline). The main outcome measurement was average grams of fruits and vegetables per lunch meal served per customer (net weight; potatoes not included).

Setting: Five workplaces in Denmark: a military base, an electronic component distributor, a bank, a town hall and a waste-handling facility.

Subjects: Work-site canteen managers, staff and customers.

Results: There were significant increases in the total consumption of fruits and vegetables for all five work-site canteens from baseline to end-point, $70 \mathrm{~g}$ per customer on average $(67,54,39,88$ and $103 \mathrm{~g}$, respectively). The follow-up data collection showed that the canteens either maintained or significantly increased consumption, the average increase being $95 \mathrm{~g}$ per customer compared with baseline (77, 60, 86, 70 and $183 \mathrm{~g}$, respectively).

Conclusions: This study demonstrates a large potential for work-site canteens to increase customers' intake of fruits and vegetables at lunch and suggests a broad spectrum of strategies to compose meals that are both rich in fruits and vegetables and attractive to customers.
\end{abstract}

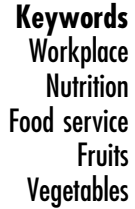

Studies have repeatedly demonstrated that consumption of fruits and vegetables reduces the risk of major cancers and cardiovascular diseases ${ }^{1-8}$. Based on a Danish report ${ }^{9}$ reviewing the major studies and reviews addressing the issue, the Danish Food Administration in 1998 recommended a daily intake of fruits and vegetables of $600 \mathrm{~g}$ or more for adults and children above 10 years old. Governmental bodies and major health organisations have since then agreed to communicate the recommendation as ' 6 a day - eat more fruits and vegetables'. It was estimated that dietary changes in accordance with these new recommendations for fruits and vegetables would lead to a $15-30 \%$ reduction in the risk of cancer and ischaemic heart disease in the Danish population. However, a substantial proportion of the population in many Western countries is still not consuming fruits and vegetables according to recommendations ${ }^{10,11}$. Joffe and Robertson ${ }^{10}$ concluded that, using the best current estimates of relative risk, over 26000 deaths before the age of 65 years would be prevented annually in the European Union if daily intake of fruits and vegetables was increased.

In order to achieve significant changes in dietary behaviour, it has been recognised that information provision alone is not enough ${ }^{12,13}$. Environmental and structural strategies are now receiving increased attention, as they create opportunities for action and remove barriers to following a healthy diet ${ }^{14}$. Likewise, the Danish ' 6 a day' research programme, launched in 1999, builds on the assumption that people will eat more fruits and vegetables if the availability of tasty, healthy choices is improved. This collaborative programme, based on public and private partnership, includes research in various settings, including studies in workplace settings. The workplace is recognised as one of the priority settings for health promotion into the 21st century because it offers major opportunities to access a large proportion of the adult 
population ${ }^{15}$. The present paper reports the results of the ' 6 a day' Work-site Canteen Model Study.

Recently, some published intervention studies at workplaces have focused on individual behaviour change and environment modifications, including workplace lunches, to achieve synergistic effects on the consumption of fruits and vegetables ${ }^{16,17}$. However, no systematic measurements have been taken in these studies to investigate the connection between the food choices as offered and the impact on consumption. The food service staff certainly have a major influence over food consumption through the range and composition of foods that they produce ${ }^{18}$. However, little is generally known about how staff are motivated to change existing practices and which practical strategies increase the consumption of fruits and vegetables.

The present model study was undertaken to (1) investigate if significant changes in the consumption of fruits and vegetables may be achieved by directly targeting work-site canteens, and (2) gain knowledge of effective strategies to increase the consumption of fruits and vegetables. Specifically, five canteens were selected to participate in the study using the tools of continuous quality improvement as a background construct, including total employee involvement and problem-solving driven by measurable data ${ }^{19,20}$.

\section{Methods}

\section{Work-site recruitment}

Five work sites with in-house food service facilities were recruited to participate in the study: a military base, an electronic component distributor, a bank, a town hall and a waste-handling facility. The recruitment took place by direct contact. Three of the canteens (the electronic component distributor, the bank and the town hall) were contacted because earlier they had shown interest towards menus containing more fruits and vegetables to some of the partners in the project. The remaining two canteens were contacted because it was considered desirable for the study to include physically active male employees. The waste-handling facility already had commenced health promotion activities at the time they were contacted by the project. The military base was selected by the Armed Forces because it showed specific interest in the project after a presentation.

Selection criteria were that the recruited facilities should: (1) serve more than 50 but less than 500 meals per day; (2) represent different working environments, including both public and private sectors; (3) represent diverse company employee groups with respect to sex distribution and occupation, from physically exacting to sedentary work; and finally (4) be led by managers who were motivated towards change. Initial contact was made with canteen managers, but canteen managers were subsequently encouraged to involve the company managers and existing canteen committees from the start.

\section{Study design}

Canteen staff were given substantial influence on the study design, in order to achieve a high level of project ownership. The study design consisted of the following seven steps.

1. A $2 \mathrm{~h}$ 'kick-off' seminar for all staff members shortly before the baseline monitoring, which briefly introduced the project and its background. The purpose was to ensure that everyone had the same information about the project and to increase staff commitment towards the project during the data collection period.

2. Baseline data collection (January/February 2001) that involved monitoring of all fruit and vegetables for a period of 3 weeks and recording the actual number of daily customers.

3. An $8 \mathrm{~h}$ training session (divided into two afternoons) for all canteen staff. Emphasis was placed on the taste and flavour of fruits and vegetables and on practical skill-building, including new and more effective ways of cutting vegetables and how to prepare a delicious buffet with lots of fruits and vegetables.

4. Goal setting (average grams of total fruit and vegetables consumed per customer per meal) by the staff and managers at each canteen. In the light of the evaluation of baseline data, the canteen staff decided which strategies to choose to reach their goals.

5. Implementation and further development of strategies. Three to four interim assessments (1 week of monitoring) followed by support visits (approximately $1.5 \mathrm{~h}$ each) were conducted during this period to evaluate the tested strategies and decide on new initiatives. The support group consisted of the research team together with selected volunteers (known as the ambassadors to the project) from work-site canteens with great experience in fruits and vegetables (start March/April 2001).

6. End-point data collection (3 weeks of monitoring) (September/October 2001).

7. Follow-up data collection (3 weeks of monitoring) after a 4-month period with no or very little contact (January/February 2002). This period of follow-up was chosen to get data exactly 1 year after the baseline monitoring, so that seasonal changes (variations) did not influence the results.

During the project period three short newsletters, mostly written by the canteen managers themselves, highlighted achievements at the canteens. In addition, canteen managers were encouraged to use existing networks to share ideas or provided with network opportunities with other catering facilities where networks did not exist. The objective was to give the managers the 
chance to share creative ideas and valuable lessons learned, as well as reinforcing and mutual support.

\section{Monitoring the consumption of fruits and vegetables}

The main outcome measure was a change in consumption of fruits and vegetables per lunch meal served per customer. All fruits and vegetables (net weight; potatoes were not included) used for lunch were weighed for three successive weeks (15 days) at each main data collection point (baseline, end-point and follow-up). In a few cases, food was not weighed due to inadequate canteen staff capacity or holidays. In addition to the three main data collection points, interim assessments were conducted (5 days of monitoring) in each of the work-site canteens to check progress.

Canteen staff were given the responsibility for measuring the consumption of fruits and vegetables and the exact number of customers. This included almost all of the staff. To facilitate the measurements, different forms were constructed and evaluated in dialogue with the staff before baseline. The forms were very simple, divided into five days (Monday to Friday), and with space provided for listing of all fruits and vegetables that were prepared for serving. Four meal component categories were weighed individually, because typically these dishes were prepared separately physically or at different times: hot dishes, cold dishes, salad bar, and fresh fruit plus vegetable-based 'snack'. One of the authors instructed staff in the data collection method and participated the first day of measuring to ensure that everyone understood the significance of making exact measurements. The amount of fruits and vegetables not being sold was noted on the form so that the total amount of fruits and vegetables per meal could be calculated.

Also, a form was worked out to count customers. The counting was performed differently from site to site depending on the service delivery system being used. At the military base the counting was done using a cash register system, at the electronic component distributor and the town hall the cashier counted the number of customers, while at the bank the number of trays being used was counted and at the waste-handling facility the orders were counted.

Completed records were checked after each round of monitoring by one of the authors and very low or high records were examined for discrepancies.

An employee questionnaire was employed at the endpoint data collection at the five work sites to determine customer satisfaction with canteen menus. Results only for sex, age and work conditions are shown in this paper.

\section{Statistical analysis}

Data on total consumption of fruits and vegetables were evaluated by analysis of variance (SAS System for Windows, version 8.01; SAS Institute, Cary, NC, USA). A significance level of $5 \%$ was used. Data are presented as mean \pm standard deviation.

\section{Results}

\section{Workplace and canteen characteristics}

Work-site canteen and employee characteristics are presented in Table 1 . Two of the workplaces were private (the electronic component distributor and the bank) and three were public (the military base, town hall and wastehandling facility).

The canteen units varied across work sites with respect to number of customers, selections available and the service delivery system. At baseline, four of the work sites had a 'cash cafeteria' system, where customers selected and purchased what they want for lunch, and one had a 'buffet' system, where a variety of food choices were offered at a fixed price.

\section{Consumption of fruits and vegetables and the strategies being used}

Changes in the consumption of fruits and vegetables from baseline to end-point and follow-up are shown in Fig. 1. There were significant and large increases in daily consumption for all canteens from baseline to end-point (increase per customer: $67 \mathrm{~g}, P<0.001 ; 54 \mathrm{~g}, P=0.01$; $39 \mathrm{~g}, P<0.001 ; 88 \mathrm{~g}, P<0.001$; and $103 \mathrm{~g}, P<0.001$, for the military base, electronic component distributor, bank,

Table 1 Characteristics of the work-site canteens and employees

\begin{tabular}{|c|c|c|c|c|c|}
\hline & Military base & $\begin{array}{l}\text { Electronic component } \\
\text { distributor }\end{array}$ & Bank & Town hall & $\begin{array}{l}\text { Waste-handing } \\
\text { facility }\end{array}$ \\
\hline \multicolumn{6}{|l|}{ Employee characteristics ${ }^{*}$} \\
\hline Sex (\% female) & 33 & 38 & 62 & 75 & 29 \\
\hline Occupation (\% physically active) $†$ & 70 & 17 & 23 & 16 & 50 \\
\hline \multicolumn{6}{|l|}{ Canteen characteristics } \\
\hline Meal service system & Cash system & Buffet system & Cash system & Cash system & Cash system \\
\hline
\end{tabular}

* Results from a customer questionnaire at end-point.

† Including the categories 'physically exacting work' and 'both physically exacting and sedentary work'.

$\ddagger$ Results from the baseline data collection. 


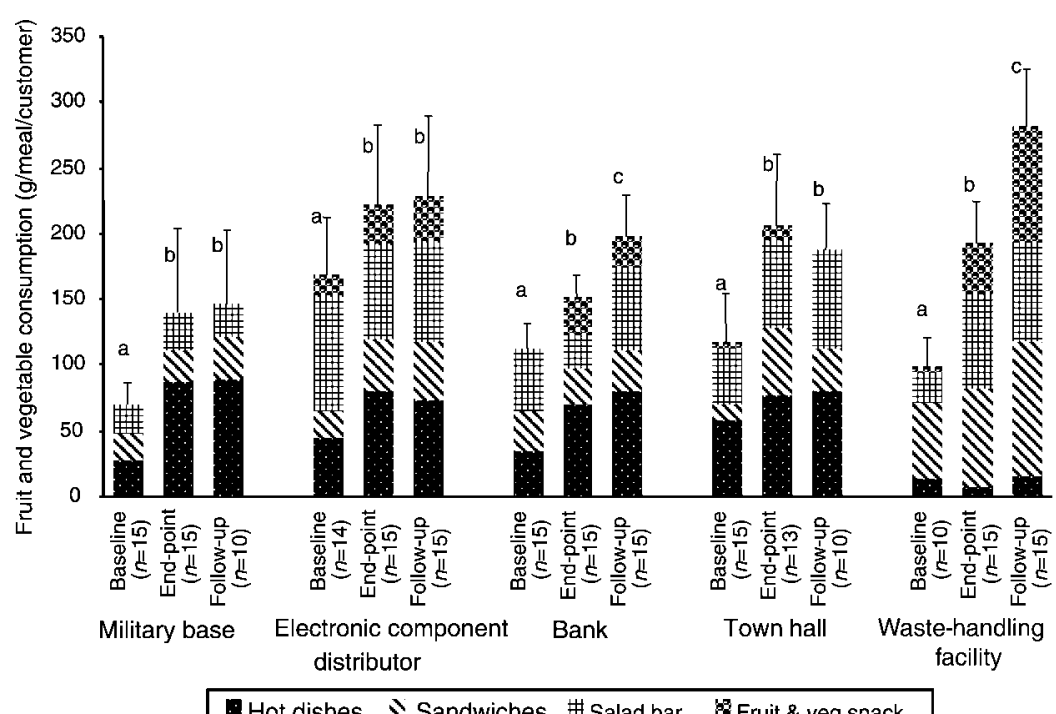

Fig. 1 Change in mean consumption of fruits and vegetables per customer at baseline (i.e. before interventions took place), at end-point (i.e. post-intervention) and after a 4-month follow-up period (1 year from baseline). Total consumption (mean \pm standard deviation) is grouped by food category. ${ }^{\mathrm{abc}}$, Means of total consumption of fruits and vegetables for each work-site canteen with different letters are significantly different $(P<0.05) ; n$, number of days of monitoring

town hall and waste-handling facility, respectively), corresponding to an increase of $70 \mathrm{~g}$ on average. The follow-up data collection (1 year after the baseline data collection and 4 months from the end-point data collection) showed that the canteens either maintained the increased consumption of fruits and vegetables (follow-up vs. end-point: 10,6 and $-18 \mathrm{~g}$ per customer for the military base, electronic component distributor and town hall, respectively; not significant) or significantly increased the consumption even more (follow-up vs. endpoint: 47 and $80 \mathrm{~g}$ per customer for the bank and wastehandling facility, respectively; $P<0.001$ for both). Average daily increase at follow-up compared with baseline was $95 \mathrm{~g}$ per customer for the five canteens.

In general, there were large variations in both baseline level of consumption of fruits and vegetables and in strategies chosen for implementation at each canteen. Table 2 lists the strategies according to categories for the different canteens.

In the military base canteen, the consumption of fruits and vegetables was the lowest at baseline, $70 \pm 17 \mathrm{~g}$ per customer; however, the consumption almost doubled during the intervention, $137 \pm 66$ and $146 \pm 55 \mathrm{~g}$ per customer at end-point and follow-up, respectively. In particular, the hot meal contributed to the increase (baseline vs. end-point: from $27 \pm 10$ to $87 \pm 42 \mathrm{~g}$ per customer, $P<0.001$ ). The major strategies chosen were to add more vegetables in stews/casseroles and in pies, to mix vegetables in roasted potatoes, rice, etc., and to introduce vegetarian meals once a week. Furthermore, mixed rich salads were offered daily in addition to the salad bar.

The canteen at the electronic component distributor already had a high consumption of fruits and vegetables at baseline, $168 \pm 44 \mathrm{~g}$ per customer. Still, the canteen succeeded in increasing consumption to $222 \pm 59$ and $228 \pm 60 \mathrm{~g}$ per customer at end-point and follow-up, respectively. In particular, the consumption of salad was high at baseline ( $86 \pm 21 \mathrm{~g}$ per customer), as the canteen staff already had an increased focus on serving appetising mixed salads. The focus during the intervention was to serve hot dishes with lots of fruits and vegetables three or four times a week (baseline vs. end-point: from $44 \pm 28$ to $80 \pm 45 \mathrm{~g}$ per customer, $P=0.02$ ). With respect to cold dishes, the consumption of fruits and vegetables was increased by adding a vegetable garnish. Furthermore, one of the original six daily meat options was replaced with a smaller vegetarian dish; for example, a vegetarian soup or a mixed fruit plate (baseline vs. end-point: from $22 \pm 14$ to $39 \pm 23 \mathrm{~g}$ per customer, $P=0.04$ ). Another strategy was to offer peeled whole carrots as a part of the buffet (fresh fruit plus vegetable snack, baseline vs. endpoint: from $17 \pm 8$ to $31 \pm 9 \mathrm{~g}$ per customer, $P=0.004$ ).

The bank canteen increased the consumption of fruits and vegetables from $112 \pm 17 \mathrm{~g}$ per customer at baseline to $151 \pm 16 \mathrm{~g}$ per customer at end-point. This canteen was able to double the consumption of fruits and vegetables in the category hot meals (baseline vs. end-point: from $34 \pm 17$ to $71 \pm 16 \mathrm{~g}$ per customer, $P<0.001)$. Vegetables were, as a rule, always served as a side dish if the hot dish did not include adequate amounts of vegetables. Furthermore, the sale of vegetable snacks and fruits was upgraded by increasing variety, and by placing fresh fruit and vegetable snacks in a more attractive place (baseline vs. end-point: from $15 \pm 3$ to $28 \pm 4 \mathrm{~g}$ per customer, $P<0.001)$. Vegetable garnish, e.g. large pieces of tomato and cucumber, were already provided before baseline free of charge. In the period between the end-point 
Table 2 Strategies chosen to increase the availability of fruits and vegetables in cold dishes, hot meals, salad bar and fresh fruit plus vegetable snacks (the canteens using the strategy are shown in parentheses)

\section{Cold dishes}

1. Use at least two different kinds of fruits and vegetables as garnish per sandwich (waste-handling facility)

2. Place fruit and vegetable garnish at the beginning of buffet and free of charge (bank)

3. Place plenty of fruit and vegetable garnish together with the meat on the same dish (electronic component distributor)

4. Use a more dense garnish, e.g. grated carrots, raw/marinated/oven-made root vegetables or slices of fresh fruit, instead of a 'light' garnish such as lettuce leaves (electronic component distributor, town hall)

5 . Increase the ratio of fruits and vegetables to meat in mixed fillings, e.g. sandwich spreads, egg dishes, etc. (bank)

6. Offer one or two different kinds of vegetarian filling every day, e.g. tomato slices and vegetarian pâté (military base, bank, waste-handling facility)

7. Spread bread with chutney or relish, e.g. aubergine purée, instead of butter or mayonnaise (electronic component distributor)

8. Offer plates with a fixed amount of fruit and vegetables, e.g. $200 \mathrm{~g}$ of fruits and vegetables, including salads and half a piece of fruit (town hall)

\section{Hot meals}

9. Replace part of the meat in stews, stir-fries and casseroles with vegetables and fruits. It adds flavour and colour, and the amount of meat served can be reduced (military base, electronic component distributor, bank, town hall)

10. Mix onions and other vegetables into ground meat dishes (e.g. meatballs and meatloaf). Not only does it improve economy, dishes become more juicy and flavourful (town hall)

11. Increase the serving size of vegetable accompaniments. Preferably serve two different kinds of vegetables, e.g. softened onions and green beans to meat, to make it more attractive to eat larger portions of vegetables (military base, bank)

12. Mix fruit and vegetables into rice, pasta, roasted potatoes and mashed potatoes (military base, electronic component distributor, bank)

13. Thicken sauces and soups with puréed vegetables (bank, town hall)

14. Serve vegetarian meals once or twice a week (military base, bank)

15. Three to four times a week focus on adding extra amount of fruits and vegetables (electronic component distributor)

16. Get inspiration from ethnic cuisines, e.g. Asian cuisines, that are known to focus on vegetables (military base, electronic component distributor)

17. Fast-food meals can also be healthy, e.g. tortillas with mashed beans, salad, etc. Such meals are very popular especially with the younger customers (electronic component distributor)

\section{Salad bar}

18. Offer appetising mixed salads in the salad bar. It is a good idea to use recipes to ensure variation (electronic component distributor)

19. Use more coarse vegetables such as cabbage and root vegetables, cooked and marinated. Cooked vegetables are easier to eat in larger portions (electronic component distributor, town hall)

20. Serve a more substantial mixed salad, including meat, fish, cheese or eggs on a plate with bread (military base, bank)

21. Try moving the salads to different places on the buffet. That way you may reach some of the traditional non-salad eaters (electronic component distributor, bank)

Fruits and vegetables as snacks

22. Sell whole fresh fruit at favourable prices, or you can offer fruit at reduced prices if customers buy more at a time (wastehandling facility)
23. Sell sliced fruit, e.g. slices or wedges of melon, pineapple or fruit, in snap-lock bags (bank)

24. Give away whole peeled vegetables (e.g. carrots) strategically located for example near customer queues (electronic component distributor, waste-handling facility)

25. Make a vegetable snack bar using, e.g., carrot, celery and courgette in slices or sticks (bank)

26. Sell snacks in bags containing $100 \mathrm{~g}$ of raw vegetables that can be brought to offices to eat in the afternoon (town hall)

27. Locate the fruit and vegetable snacks in a more attractive place (bank)

28. Serve more fruit-based desserts (electronic component distributor)

measurement and the follow-up, the canteen changed the meal service system to a buffet system. During this period the follow-up measurement showed that the consumption increased to an even higher level (198 $\pm 31 \mathrm{~g}$ per customer), in particular due to a higher consumption of salad (baseline vs. follow-up: from $31 \pm 6$ to $64 \pm 14 \mathrm{~g}$ per customer, $P<0.001$ ).

The town hall canteen increased the consumption of fruits and vegetables from $118 \pm 36 \mathrm{~g}$ per customer at baseline to $206 \pm 54$ per customer at end-point. The amount of fruits and vegetables increased in the salad bar (baseline vs. end-point: from $43 \pm 13$ to $68 \pm 22 \mathrm{~g}$ per customer, $P=0.001$ ), and slightly but not significantly in the hot dishes (baseline vs. end-point: from $59 \pm 35$ to $77 \pm 35$ per customer, not significant). However, the largest increase was in the cold dishes (baseline vs. endpoint: from $11 \pm 3$ to $50 \pm 15 \mathrm{~g}$ per customer, $P<0.001$ ). This increase was mainly due to serving dishes with a fixed amount of fruits and vegetables (100 $\mathrm{g}$ or $200 \mathrm{~g}$ per plate). In addition, snack bags with $100 \mathrm{~g}$ of vegetables were offered. This canteen, like the bank, changed its meal service system to a buffet system after the end-point measurement, which seemed to cause a decrease (although not significant) in the total consumption of fruits and vegetables at the follow-up measurement (188 $\pm 34 \mathrm{~g}$ per customer). The decrease was mainly due to a lower consumption in the cold dishes. Also, fresh fruit and vegetable snacks were no longer offered at the followup measurement. Now both these options have been reintroduced in the canteen.

Consumption of fruits and vegetables in the canteen at the waste-handling facility increased from $99 \pm 20 \mathrm{~g}$ per customer at baseline to $202 \pm 21 \mathrm{~g}$ per customer at endpoint. Consumption measured at follow-up increased further to $282 \pm 42 \mathrm{~g}$ per customer. The assortment was mainly based on open sandwiches. Hot meals were only served once a week. Therefore, efforts in this canteen were to give extra focus to garnish (baseline vs. end-point: from $57 \pm 11$ to $72 \pm 12$ g per customer, $P=0.04$ ), using a different type of garnish on every open sandwich. In addition, a salad bar was established, resulting in a threefold increase in consumption in this category (baseline vs. end-point: from $22 \pm 6$ to $74 \pm 20 \mathrm{~g}$ customer, $P<0.001$ ). Two very popular initiatives were fruits offered with 50\% discount and peeled carrots free of 
charge (fresh fruit and vegetable snack, baseline vs. endpoint: from $6 \pm 2$ to $39 \pm 8 \mathrm{~g}$ per customer, $P<0.001$; increasing to $74 \pm 15 \mathrm{~g}$ per customer at follow-up, $P<0.001)$.

\section{Discussion}

All five canteens in the present study succeeded in significantly increasing the daily amounts of fruits and vegetables served, although representing very different baseline intakes (from 70 to $168 \mathrm{~g}$ per customer) and various work-site employee profiles (e.g. with respect to sex, age and work conditions). A net average increase of $70 \mathrm{~g}$ of fruits and vegetables per customer (equivalent to 0.7 servings) was achieved from baseline to end-point. The follow-up measurements showed that changes were maintained in the canteens, with an average increase of $95 \mathrm{~g}$ per customer (approximately 1 serving) compared with baseline.

The strategies chosen by the canteen staff to increase fruits and vegetables encompassed a broad spectrum, depending on factors like customer profiles and baseline consumption. Most canteens targeted the hot dish food category, and used strategies such as adding more fruits and vegetables in stews and meat balls, etc., serving different kinds of garnish based on fruits and vegetables to meat, and mixing vegetables with rice, pasta and potatoes to increase the consumption. Inspiration was found in ethnic cuisines incorporating traditional as well as modern dishes. Strategies such as serving appetising mixed salads; inclusion of cooked vegetables and more 'dense' vegetables like beans, root vegetables, etc. in dishes; attracting 'new' customers by placing some of the salads near the hot dishes rather than only in the salad bar, were all successful. The results indicate that it might be easier to get customers to choose more salad when it is part of a buffet compared with a cash system, where the customers select and purchase each item they want for lunch. Generally, canteen staff found that cold dishes, mainly consisting of open sandwiches, were the most difficult category in which to increase the content of fruits and vegetables. Nevertheless, canteens did increase fruits and vegetables in cold dishes especially by increasing the amount and type of garnish (e.g. root vegetables and fruit slices instead of lettuce leaves, etc.), and one canteen offered plates with a fixed amount of fruits and vegetables. Peeled free-of-charge carrots were successful in two maledominated work sites. Also, reducing the price of fresh fruits was a successful strategy. Analogously, Jeffery et al. ${ }^{21}$ achieved an increase of approximately threefold in fruit and salad purchases in a cafeteria when prices were reduced by $50 \%$ and the number of choices increased.

Dietary intake studies of this kind may, of course, be unreliable and inaccurate. However, great emphasis was given on instructing the staff and clarifying ambiguous entries and incomplete records. Furthermore, in order to increase data reliability and prevent deliberate alternations of food preparation, each main data collection point proceeded for a 3-week period. Accuracy can only be known if the true value of the measurement is known. A systematic error in the dietary measures taken by the canteen staffs may be difficult to counter; however, the authors are convinced that the food service staff were very committed and did not 'embellish' the results.

In three of the canteens a certain reduction in the number of customers was recorded during the study. However, the reductions were concordant with corresponding reductions in staff. A survey at the end of the study among employees supported the notion that the reduction in the number of customers was not caused by changes in the canteen supplies: frequent users as well as the those who rarely used the canteen expressed satisfaction with the increased amount of fruit and vegetables in the canteen food.

A limitation of the present study is that no intake data are available at the individual level, since the results are based on the total consumption of fruits and vegetables in the canteens related to the number of customers. It is likely that the results conceal large variations between customers, e.g. customers who chose to eat from the salad bar generally consumed more vegetables than customers who chose to eat sandwiches only. The study focuses on lunchtime consumption of fruit and vegetables, and thus no information is gathered on the impact of increasing consumption at lunch on the nutritional quality of the employee's total diet.

Individual intake of fruits and vegetables as an output measure has been assessed in several workplace healthpromotion intervention programmes addressing both individual behavioural and environmental changes. In the Working Well Trial ${ }^{22,23}$, the interventions directed at individuals emphasised awareness, active change and maintenance activities concerning dietary changes and smoking cessation. The interventions targeting the worksite environment with respect to nutrition included the formulation of catering policies and changes in the variety of food offered at cafeterias and in vending machines, i.e. labelling on items meeting specified criteria on fat or fibre. Results showed a daily increase in intake of fruits and vegetables of 0.18 servings per person. Similarly, the Seattle 5 a Day Worksite Program ${ }^{24}$ included both individual and environmental targets for change, but in this study focus was solely on changes in consumption of fruits and vegetables. Intake increased by 0.5 daily servings in the intervention work sites, all with cafeterias; however, only by 0.3 servings when compared with the control work sites. Changes in the cafeterias were encouraged, including point-of-purchase displays, signs identifying foods as 5 a Day foods, and some offered incentives for eating more fruits and vegetables. Plate observation at cafeteria checkout lines revealed an average increase of 0.4 servings in the intervention work 
sites and 0.24 in the control work sites, indicating that a larger part of the observed increase in intake could be assigned to changes carried out in the cafeterias. The Treatwell 5-a-Day Study ${ }^{25}$ showed that involving family members could be a promising strategy to increase intake of fruits and vegetables. In this study, an increase of approximately 0.2 servings was achieved in the work-site intervention group compared with the minimum intervention control group. However, a larger intervention effect of approximately 0.5 servings was achieved in the work site-plus-family intervention group.

Intervention studies targeting the food service units more specifically include studies in schools, in particular aiming at lowering total fat content. The Eat Smart Food Service Program ${ }^{26}$ succeeded in reducing the percentage of energy from fat by 4.1 in intervention compared with control school lunches. This was obtained by targeting the food service staff and administrators through training sessions, educational materials and ongoing support visits. Also, a bimonthly newsletter highlighting achievements at individual schools was provided. A recent study, the Peterborough Schools Nutrition Project ${ }^{27}$, demonstrated the difficulty in achieving sustained dietary changes in eating habits. Dietary targets were to increase both availability and the number of pupils consuming specific food items, i.e. fresh fruit, vegetables and salad, high-fibre bread, non-fried potatoes and noncream cakes. Some positive changes were made, with some of the dietary targets being achieved at an early stage but not sustained. The authors concluded that a need exists for research into other intervention strategies, particularly targeting changes at the level of food production. They also pointed out that the presence and support of the catering managers were extremely important.

Awards have been the object of some health promotion projects as a way to provide motivation and support for food services wishing to make changes in the nutritional quality of the food offered. Specifically, food services that meet certain health promotion standards receive an award and free promotion in the community for providing a healthier environment. Examples of this are 'Eat Smart! Ontario's Healthy Restaurant Program' and the Heartbeat Award schemes ${ }^{28-30}$. The findings by Warm et $a l .{ }^{31}$ suggest that the Heartbeat Award Scheme in England may increase consumer choices on healthy options, but it is not possible to draw conclusions about the impact of the scheme on consumers' eating habits. Carter and Swinburn ${ }^{32}$, on the other hand, found that the number of Heartbeat Awards in New Zealand schools was significantly associated with a reduction in the sales of items like doughnuts and sweets, and an increase in sales of sandwiches and filled rolls, but not in the sales of fruits.

We suggest that many factors were critical to the success of this study. First of all, the attitude of management is central to overcome barriers to change. Key elements include empowering the staff and getting everyone involved proactively in the processes ${ }^{33,34}$. Therefore, intervention goals and activities were decided individually by each of the work-site canteens. All staff members participated in self-monitoring, goal setting and decision-making, which also increased staff commitment to the project. In addition, self-monitoring implied that each staff member's knowledge and creativity was challenged. Focus was placed on effect, i.e. the amount of fruits and vegetables consumed instead of simply the presence of the vegetables. Furthermore, the messages to the work-site canteens were stated in positive culinary terms, as the major motivator to make dietary changes is unlikely to be the health benefits, but rather sensory appeal and attractiveness ${ }^{13}$. Similarly, instead of labelling the healthy food choices, staffs made efforts to strengthen their culinary skills in preparing fruits and vegetables.

In conclusion, this study shows that there is a large potential for work-site canteens to increase the consumption of fruits and vegetables. Work-site canteens, therefore, seem to be a very promising channel for influencing employees' dietary habits, by making fruits and vegetables more accessible and appealing at lunch meals. The work sites in the study were not randomly selected and are probably more motivated than an average canteen. This limits generalisation of the results, however the results are encouraging. Even though there were large variations between the different customer groups in the five canteens, all of the canteens succeeded in increasing the consumption of fruit and vegetables considerably. Further research should include a control group and involve more canteens to identify key strategies for different types of canteens and customer profiles. Furthermore, a follow-up period of 1 year is desirable in order to investigate if the effect is lasting. Efforts should focus on ways to increase staff motivation and ownership to obtain the maximum effect in nutrition intervention programmes.

\section{Acknowledgements}

The collaborative study, which included the Danish Veterinary and Food Administration, the Danish Cancer Society, the Danish Fruit, Vegetable and Potato Board and the Danish Gardening Marketing Board (GAU), was supported by The Directorate for Food, Fisheries and Agri Business. We thank all those who took part in the project, especially the managers and staff at the five model worksite canteens, and the three project 'ambassadors' and canteen managers - Britta Rolsting, Birte Brorson and Jan Holm - for their impressive involvement throughout the research process. We also thank the following for their support and contributions: Morten Strunge Meyer, Robert Pederson and Janne Bagger from the Danish Cancer 
Society, and Anne Marie Beck from the Danish Veterinary and Food Administration.

\section{References}

1 Steinmetz KA, Potter JD. Vegetables, fruit, and cancer. I. Epidemiology. Cancer Causes \& Control 1991; 2: 325-57.

2 Block G, Patterson B, Subar A. Fruit, vegetables, and cancer prevention: a review of epidemiological evidence. Nutrition and Cancer 1992; 18: 1-29.

3 Ness AR, Powles JW. Fruit and vegetables, and cardiovascular disease: a review. International Journal of Epidemiology 1997; 26: 1-13.

4 Jansen MCJF, van't Veer P, Kok FJ. Fruits and Vegetables in Chronic Disease Prevention. Rationale for Fruits and Vegetables - Campaign. Wageningen, The Netherlands: Landouwuniversitet Wageningen, 1995.

5 Law MR, Morris JK. By how much does fruit and vegetable consumption reduce the risk of ischaemic heart disease? European Journal of Clinical Nutrition 1998; 52: 549-56.

6 van't Veer P, Jansen MCJF, Klerk M, Kok FJ. Fruits and vegetables in the prevention of cancer and cardiovascular disease. Public Health Nutrition 2000; 3: 103-7.

7 Joshipura KJ, Ascherio A, Manson JE, Stampfer MJ, Rimm EB, Speizer FE, et al. Fruit and vegetable intake in relation to risk of ischemic stroke. Journal of the American Medical Association 1999; 282: 1233-9.

8 Joshipura KJ, Hu FB, Manson JE, Stampfer MJ, Rimm EB, Speizer FE, et al. The effect of fruit and vegetable intake on risk for coronary heart disease. Annals of Internal Medicine 2001; 134: 1106-14.

9 Trolle E, Fagt S, Ovesen L. Frugt og grontsager. Anbefalinger for indtagelse [Fruits and Vegetables. Recommended Intake]. Copenhagen: Danish Veterinary and Food Administration, 1998.

10 Joffe M, Robertson A. The potential contribution of increased vegetable and fruit consumption to health gain in the European Union. Public Health Nutrition 2001; 4: 893-901.

11 Subar AF, Heimendinger J, Patterson BH, Krebs-Smith SM, Pivonka E, Kessler R. Fruit and vegetable intake in the United States: the baseline survey of the Five A Day for Better Health Program. American Journal of Health Promotion 1994; 9: 352-60.

12 Stockley L (Rapporteur). Working Party 3: Final report. Toward public health nutrition strategies in the European Union to implement food based dietary guidelines and to enhance healthier lifestyles. Public Health Nutrition 2001; 4 : 307-24.

13 Eertmans A, Baeyens F, Van den Bergh O. Food likes and their relative importance in human eating behavior: review and preliminary suggestions for health promotion. Health Education Research 2001; 16: 443-56.

14 Glanz K, Mullis RM. Environmental interventions to promote healthy eating: a review of models, programs, and evidence. Health Education Quarterly 1988; 15: 395-415.

15 Chu C, Breucker G, Harris N, Stitzel A, Gan X, Gu X, et al. Health-promoting workplaces - international settings development. Health Promotion International 2000; 15: $155-67$.

16 Buller DB, Hunt MK, Sorensen G, Beresford S. The 5 A Day Worksite Program. In: National Institutes of Health, ed. $5 \mathrm{~A}$ Day for Better Health Program. Bethesda, MD: NIH Publication, 2001; 129-32.
17 Havas S, Heimendinger J, Damron D, Nicklas TA, Cowan A, Beresford SAA, et al. 5 a Day for Better Health - nine community research projects to increase fruit and vegetable consumption. Public Heath Reports 1995; 110: 68-79.

18 Société Française de Santé Publique. Health and Human Nutrition: Element for European Action. Vandoevre, France: Collection Santé \& Société, 2000.

19 Robidoux LW, Sankaran G. Managing nutrition services in nursing homes: is continuous quality improvement a key to survival? Journal of Nutrition for the Elderly 1998; 17: 41-57.

20 Cook S, Sinclair D. Emergency department triage: a program assessment using the tools of continuous quality improvement. Journal of Emergency Medicine 1997; 15: 889-94.

21 Jeffery RW, French SA, Raether C, Baxter JE. An environmental intervention to increase fruit and salad purchases in a cafeteria. Preventive Medicine 1994; 23: 788-92.

22 Abrams DB, Boutwell WB, Grizzle J, Heimendinger J, Sorensen G, Varnes J. Cancer control at the workplace: the Working Well Trial. Preventive Medicine 1994; 23: 15-27.

23 Sorensen G, Thompson B, Glanz K, Feng Z, Kinne S, DiClemente $\mathrm{C}$, et al. Work site-based cancer prevention: primary results from the Working Well Trial. American Journal of Public Health 1996; 86: 939-47.

24 Beresford SAA, Thompson B, Feng Z, Christianson A, McLerran D, Patrick DL. Seattle 5 a Day Worksite Program to increase fruit and vegetable consumption. Preventive Medicine 2001; 32: 230-8.

25 Sorensen G, Stoddard A, Peterson K, Cohen N, Hunt MK, Stein E, et al. Increasing fruit and vegetable consumption though worksites and families in the Treatwell 5-a-Day Study. American Journal of Public Health 1999; 89: 54-60.

26 Osganian SK, Ebzery MK, Montgomery D, Nicklas TA, Evans MA, Mitchell PD, et al. Changes in the nutrient content of school lunches: results from the CATCH Eat Smart Food Service Intervention. Preventive Medicine 1996; 25: 400-12.

27 Parker L, Fox A. The Peterborough Schools Project: a multiple intervention programme to improve school-based eating in secondary schools. Public Health Nutrition 2001; 4: $1221-8$.

28 MacAskill L, Dwyer JJM, Uetrecht C, Dombrow C, Crompton $\mathrm{R}$, Wilck B, et al. An evaluation assessment to develop a restaurant health promotion program in Canada. Health Promotion International 2000; 15: 57-69.

29 Snowdon W. Bedfordshire Heartbeat Award: research into caterer and customer perceptions of this award. Journal of Health Education 1998; 36: 60-3.

30 Peach R, Dehar M-A, Casswell S, Gourley G. Heartbeat Awards in intermediate and secondary schools in New Zealand: outcomes of the first two years. Health Promotion Journal of Australia 1996; 6: 42-50.

31 Warm DL, Rushmere AE, Margetts BM, Kerridge L, Speller VM. The Heartbeat Award Scheme: an evaluation of catering practices. Journal of Human Nutrition and Dietetics 1997; 10: $171-9$.

32 Carter M-A, Swinburn B. Measuring the impact of a school food programme on food sales in New Zealand. Health Promotion International 1999; 14: 307-16.

33 Ugboro IO, Obeng K. Top management leadership, employee empowerment, job satisfaction, and customer satisfaction in TQM organizations: an empirical study. Journal of Quality Management 2000; 5: 247-72.

34 Dess GG, Picken JC. Changing roles: leadership in the 21st century. Organizational Dynamics 2000; 28: 18-33. 